\title{
EVALUATION OF THE IN VITRO ANTIMICROBIAL ACTIVITY OF AN ETHANOL EXTRACT OF BRAZILIAN CLASSIFIED PROPOLIS ON STRAINS OF Staphylococcus aureus
}

\section{Lucila Coelho Pamplona-Zomenhan ${ }^{1}$, Beatriz Coelho Pamplona ${ }^{2}$, Cely Barreto da Silva ${ }^{3}$, Maria Cristina Marcucci ${ }^{4}$, Lycia Mara Jenné Mimica ${ }^{1}$}

${ }^{1}$ Laboratório de Microbiologia, Santa Casa de São Paulo, Faculdade de Ciências Médicas, São Paulo, SP, Brasil; ${ }^{2}$ Novo Mel Indústria e Comércio Exterior Ltda, São Paulo, SP, Brasil; ${ }^{3}$ Serviço de Controle de Infecção Hospitalar, Irmandade da Santa Casa de Misericórdia de São Paulo, São Paulo, SP, Brasil; ${ }^{4}$ Universidade Bandeirantes, São Paulo, SP, Brasil.

Submitted: October 29, 2009; Returned to authors for corrections: February 03, 2010; Approved: May 30, 2011.

\begin{abstract}
Staphylococcus aureus (S. aureus) is one of the most frequent causes of hospital acquired infections. With the increase in multiple drug resistant strains, natural products such as propolis are a stratagem for new product discovery. The aims of this study were: to determine the in vitro antimicrobial activity of an ethanol extract of propolis; to define the $\mathrm{MIC}_{50}$ and $\mathrm{MIC}_{90}$ (Minimal Inhibitory Concentration - MIC) against 210 strains of S. aureus; to characterize a crude sample of propolis and the respective ethanol extract as to the presence of predetermined chemical markers. The agar dilution method was used to define the MIC and the high performance liquid chromatography (HPLC) method was used to characterize the samples of propolis. MIC results ranged from 710 to $2,850 \mu \mathrm{g} / \mathrm{mL}$. The $\mathrm{MIC}_{50}$ and $\mathrm{MIC}_{90}$ for the 210 strains as well as the individual analysis of American Type Culture Collection (ATCC) strains of Methicillin-susceptible Staphylococcus aureus (MSSA) and Methicillin-resistant Staphylococcus aureus (MRSA) were both 1,420 $\mu \mathrm{g} / \mathrm{mL}$. Based on the chromatographic analysis of the crude sample and ethanol extracted propolis, it was concluded that propolis was a mixture of the BRP (SP/MG) and BRP (PR) types. The results obtained confirm an antimicrobial activity in relation to the strains of the $S$. aureus tested.
\end{abstract}

Key words: Propolis; Staphylococcus aureus; Antimicrobial Activity.

\section{INTRODUCTION}

S.aureus is one of the most frequent causes of hospital acquired endemics and epidemics with significant levels of morbidity and mortality. Worldwide, multidrug resistant strains of Staphylococcus have become more common. A number of
$10 \%$ to $40 \%$ out of tested hospital patients or outpatients presented S.aureus in the nasal region. These colonizing microorganisms act as reservoirs, cause endogenous infections and can be spread to other patients (18). Therefore, natural products offer an alternative strategy for the discovery of new medications.

*Corresponding Author. Mailing address: Rua Campevas, 404 ap. 42 - Bairro: Perdizes - CEP: 05016-010.; Tel.: (55+11) 3571-3507 / 3367-4777 Fax: (55+11) 3223-8368.; E-mail: lu.pamplona@ig.com.br 
Propolis has been extensively studied for its antimicrobial properties. While the antimicrobial activity of ethanol extracted propolis has been demonstrated, there are few studies concerned with MRSA (11).

The chemical composition of propolis depends on geographic and climatic conditions, local flora, and bee's genetic variability $(1,2,17)$. Brazilian propolis can be classified according to chemical markers, corresponding to the geographic region from which bees collected vegetal resins, which are divided into four types: BRG, BRP (PR), BRP (SP/MG) and BRPG. The last type represents a combination of groups BRP (PR) and BRG, with components of each one (9).

Propolis defends bees against infections; therefore, antibacterial and antifungal activities are present in different samples $(1,2,7)$. The chemical components responsible for such activities are different, but they produce similar results (1, 17). The lack of standardization of the chemical composition of propolis makes it a good antimicrobial candidate, as this prevents the development of microbial resistance (14).

Comparative studies are important to standardize propolis for future therapeutic uses. These results will correlate certain chemical compositions of different propolis with specific biological activities, and thus clinical indications for use. The general public could benefit from propolis as a part of Complementary and Alternative Medicine (1).

Synergism in vitro between propolis and antimicrobial drugs has been investigated, and formulas associating propolis with antibiotics are of potential medical interest. Due to the possible development of drug resistance by bacteria, such synergism is relevant and shows that propolis could be a viable treatment option for these pathogens (5). Propolis combined with antimicrobial agents could allow lower doses of the included antibiotic, besides potentializing the drug and thus its medical potential, especially for topical use (17).

Controlled clinical studies will be necessary to define the actual synergism between ethanol extracted propolis and other drugs. Such studies could encourage the clinical association of antimicrobial drugs with propolis extracts for staphylococcal infections (5).

The aim of this study was: to determine the in vitro antimicrobial activity of an ethanol extract of propolis against Staphylococcus aureus strains and to define the $\mathrm{MIC}_{50}$ and $\mathrm{MIC}_{90}$ as well as characterize crude propolis and the respective ethanol extract among the groups BRG, BRP (PR), BRP (SP/MG) and BRPG according to the presence of predefined chemical markers (9).

\section{MATERIALS AND METHODS}

\section{Propolis}

Crude propolis samples and their respective ethanol extracts (PEE) were provided by Novo Mel ${ }^{\circledR}$. The crude propolis was sourced from the city of União da Vitória - State of Paraná, Brazil. The alcohol level and concentration of dry extract in the PEE sample were $73^{\circ}$ GL (\% volume / volume) and $22.8 \%$, respectively.

\section{Characterization of Propolis}

The high performance liquid chromatography (HPLC) method was used to characterize the propolis samples (8). The crude propolis and extracts were analyzed at dilutions ranging from $1 \%$ to $10 \%$ (Diluent: chromatographic grade methanol Merck $\left({ }^{\circledR}\right)$. Analyses were performed on a high-efficiency liquid chromatograph with a network of photodiodes and Merck-Hitachi model D-7000 automatic injector. Chromatographic conditions were:

- Mobile phase: water-formic acid PA - Merck ${ }^{\circledR}$ solution diluted at the proportion of 95:5 (Solvent A) and chromatographic grade methanol - Merck ${ }^{\circledR}$ (Solvent B)

- Elution flux: $1 \mathrm{~mL} / \mathrm{min}$ using linear gradient

- Maximum analysis time: 50 minutes

- Detection: wavelengths of $280 \mathrm{~nm}$ and $340 \mathrm{~nm}$

Specific software was used for interpreting the results (TIP $®)$.

\section{Staphylococcus aureus Strains}

The 210 strains (clinical isolate) used in this study were 
obtained from the Bacterial Library of the Microbiology Laboratory, Department of Pathology, Santa Casa de São Paulo - School of Medical Sciences. These had previously been isolated and identified as either MRSA or MSSA.

The tests and interpretations of susceptibility were done according to the Clinical and Laboratory Standards Institute (CLSI) protocol (4).

\section{Inocula}

Inocula were prepared by direct colony suspension as recommended by CLSI (3). Strains of Staphylococcus aureus were inoculated in Mueller Hinton agar and incubated in a sterilizer regulated between $35^{\circ} \mathrm{C} \pm 2{ }^{\circ} \mathrm{C}$ for 18 to 24 hours. Bacterial suspensions in sterile saline solution were prepared from direct colonies. These suspensions were adjusted to a turbidity level of $0.5 \mathrm{McF}$ arland, or $1.5 \times 10^{8} \mathrm{CFU} / \mathrm{mL}$. Subsequently, these were diluted in sterile saline 1:10 to yield a concentration of $10^{7} \mathrm{UFC} / \mathrm{mL}$. Using a Steers replicator, the individual volume distributed was about $2 \mu \mathrm{L}$, giving a final concentration of around $10^{4} \mathrm{CFU} / \mathrm{mL}$ for each inoculum inoculated onto agar.

\section{Serial Dilution of Propolis Extract}

Serial dilutions of ethanol extracted propolis were made using purified sterile water as a diluent. Equal volumes of water and extract were homogenized together yielding the first dilution (1:2). Further equal volumes of these solutions and more diluents were used to obtain dilution up to $1: 128$.

\section{Determination of Minimum Inhibitory Concentration}

The agar dilution method was used to determine MIC. Using dehydrated Mueller Hinton as a base, the medium was separated according to the manufacturer's recommendations (Himedia ${ }^{\circledR}$ ). After dissolution and homogenization of the medium, $19 \mathrm{~mL}$ were distributed in glass vials and autoclaved at $121^{\circ} \mathrm{C}$ for 15 minutes. When the temperature of culture medium reached between $45^{\circ} \mathrm{C}$ to $50^{\circ} \mathrm{C}, 1.0 \mathrm{~mL}$ of the serial dilutions of extracted propolis or $1.0 \mathrm{~mL}$ of purified sterile water was added, under aseptic conditions, to perform growth tests of the analyzed strains. The supplemented mediums were homogenized and inverted over $90 \mathrm{~mm}$. sterile labeled Petri dishes.

The antimicrobial agent stability and the reproducibility of the method were evaluated simultaneously in all the analyses performed, using an inoculation of the strains ATCC of $S$. aureus (MSSA - 29213 and MRSA - 33511).

Immediately after homogenization, using an automatic pipette and disposable tips, a volume of $350 \mu \mathrm{L}$ was distributed in the respective wells of an inoculation plate of the Steers replicator. All strains used in the experiment were inoculated only once.

Inoculations were done initially in plates without antibiotic (blanks) to evaluate the strain viability, followed by inoculations onto plates of increasing concentrations of diluted propolis extract. Finally, a second growth promoting plate was inoculated to ensure the absence of contamination or significant load of antimicrobial agent during the inoculations.

The plates were inverted and incubated under sterile conditions at a temperature of $35^{\circ} \mathrm{C} \pm 2^{\circ} \mathrm{C}$ for 24 hours.

The minimal concentration of antibacterial agent capable of complete bacterial growth inhibition was defined as the minimal inhibitory concentration (MIC). The minimal inhibitory concentration of PEE promoting growth inhibition of $50 \%$ and $90 \%$ of the strains under study were denoted $\mathrm{MIC}_{50}$ and $\mathrm{MIC}_{90}$, respectively.

This study was approved by the Research Ethics Committee of Irmandade da Santa Casa de Misericórdia de São Paulo (The São Paulo Charity Hospital Association).

\section{Statistical Treatment}

The aims of this work were to determine $\mathrm{MIC}_{50}$ and $\mathrm{MIC}_{90}$, and to characterize propolis using only the mathematical tools outlined above, dispensing with the need for sophisticated statistical treatment. 


\section{RESULTS}

The Minimum Inhibitory Concentrations of propolis ethanol extract were between 710 to $2,850 \mu \mathrm{g} / \mathrm{mL}$ (Graph 1).

The $\mathrm{MIC}_{50}$ and the $\mathrm{MIC}_{90}$ were equal for the 210 strains studied as well as the individual strains of MSSA and MRSA $(1,420 \mu \mathrm{g} / \mathrm{mL})$.

Inoculation of ATCC strains of S. aureus (MSSA - 29213 and MRSA - 33511) in all studies of MIC, evaluation of antimicrobial agent stability, and reproducibility of the method, produced identical results in all tests. The MIC for both strains of ATCC was $1,420 \mu \mathrm{g} / \mathrm{mL}$.

Chromatographic analysis of crude sample propolis and its ethanol extract enabled detection and quantification of the chemical components described in Table 1.

Table 1. Levels of selected chemical markers in a crude sample of propolis and its ethanol extract

\begin{tabular}{|c|c|c|c|c|}
\hline \multirow[b]{2}{*}{ Chemical Composition } & \multicolumn{2}{|c|}{ Crude sample } & \multicolumn{2}{|c|}{ PEE } \\
\hline & $\begin{array}{l}\text { Mean } \\
(\mathrm{mg} / \mathrm{g})\end{array}$ & $\begin{array}{l}\text { Standard } \\
\text { Deviation }\end{array}$ & $\begin{array}{c}\text { Mean } \\
(\mathrm{mg} / \mathrm{mL})\end{array}$ & $\begin{array}{l}\text { Standard } \\
\text { Deviation }\end{array}$ \\
\hline 3-[4-hydroxy-3-(oxobutyl)-phenylacrylic acid & 3.355 & 0.053 & 0.855 & 0.014 \\
\hline 3-prenyl-3(E)-(4-hydroxy-3-methyl-2-butenol)-5--prenylcinnamic acid & 0.119 & 0.009 & 0.662 & 0.002 \\
\hline 3-prenyl-4-(2-methylpropionyloxi)cinnamic acid & 0.698 & 0.025 & 0.185 & 0.016 \\
\hline 3-prenyl-4-dihydrocynamoiloxicinnamic acid & 0.211 & 0.004 & 0.200 & 0.000 \\
\hline Dihydrokaemferide & 0.312 & 0.005 & 0.341 & 0.018 \\
\hline 3-prenyl-4-hydroxycinnamic acid & 1.891 & 0.013 & 3.239 & 0.090 \\
\hline Caffeic acid & 0.292 & 0.001 & 0.125 & 0.006 \\
\hline Caffeoylquinic acid 1 & 0.555 & 0.680 & 0.364 & 0.007 \\
\hline Caffeoylquinic acid 2 & 0.684 & 0.564 & 0.081 & 0.023 \\
\hline Caffeoylquinic acid 3 & 1.357 & 1.554 & 0.632 & 0.004 \\
\hline Caffeoylquinic acid 4 & 2.491 & 0.000 & 0.087 & 0.000 \\
\hline Caffeoylquinic acid 5 & 0.426 & 0.002 & - & - \\
\hline Cinnamic acid & 8.084 & 0.138 & 3.484 & 0.010 \\
\hline p-coumaric acid & 10.201 & 0.909 & 5.081 & 0.091 \\
\hline Kaempferide & 4.511 & 0.073 & 1.248 & 0.029 \\
\hline Kaempferol & 0.528 & 0.025 & 0.372 & 0.000 \\
\hline Betuletol & 4.175 & 0.029 & 1.441 & 1.695 \\
\hline 2.2-dimethyl-6-carboxyethenyl-2H-1-benzopirane & 4.093 & 0.002 & 2.612 & 0.056 \\
\hline 2.2-dimethyl-8-prenyl-2H-1-benzopirano-6-propenoic acid & 1.639 & 0.052 & 1.019 & 0.002 \\
\hline $\begin{array}{l}\text { (E)-3-\{4-hydroxy-3-[(E)-4-(2.3)-dihydrocynamoiloxi-3-methyl-2- } \\
\text { butenyl]-5-prenylphenyl-2-propenoic acid }\end{array}$ & 1.710 & 0.019 & 0.580 & 0.545 \\
\hline 3.4-dihydroxy-5-prenylcinnamic acid & 1.486 & 0.030 & 0.769 & 0.313 \\
\hline 3.5-diprenyl-4-hydroxycinnamic acid & 19.627 & 0.428 & 11.525 & 0.078 \\
\hline Total & 68.446 & & 34.903 & \\
\hline
\end{tabular}




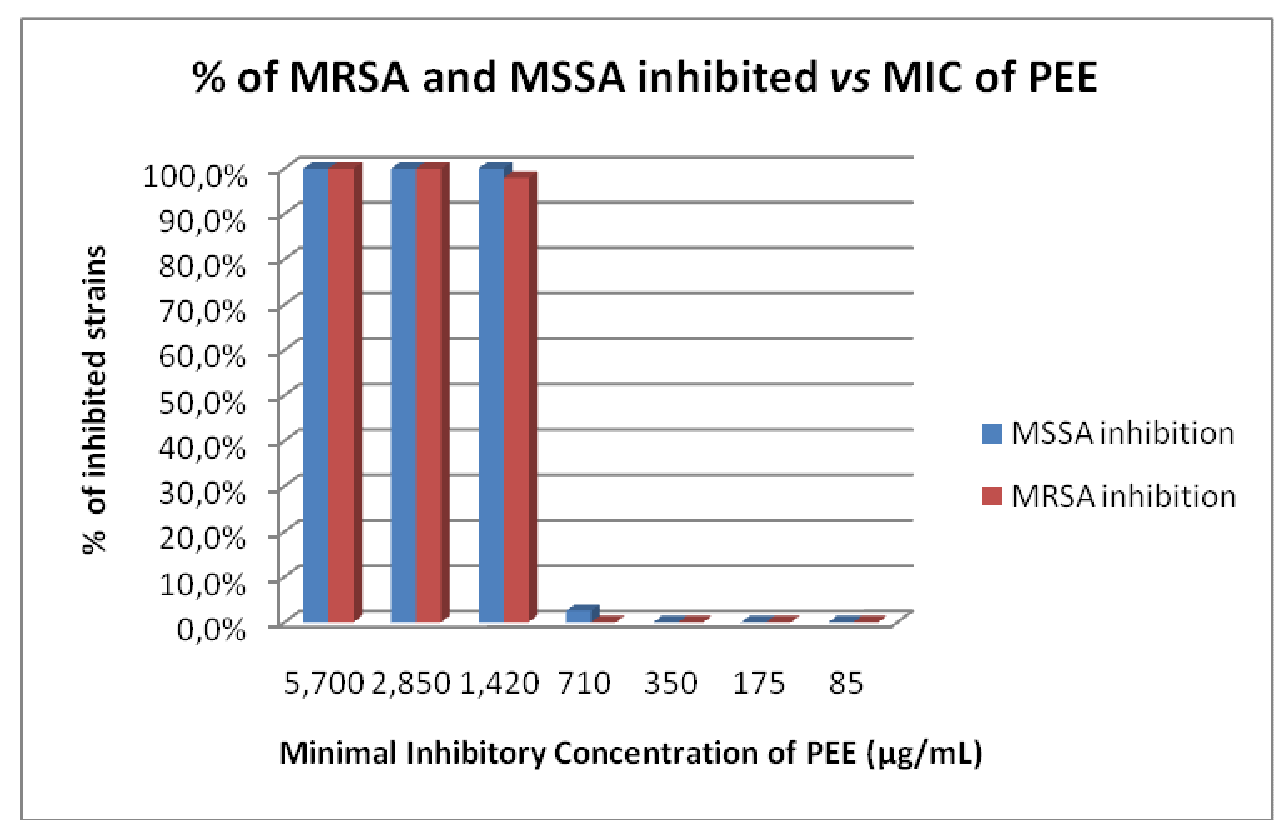

Graph 1. Distribution of inhibition caused by a propolis ethanol extract against MSSA (n=162) and MRSA ( $\mathrm{n}=48)$ strains.

\section{DISCUSSION}

The $\mathrm{MIC}_{50}$ and the $\mathrm{MIC}_{90}$ were equal for the 210 strains studied as well as the individual strains of MSSA and MRSA $(1,420 \mu \mathrm{g} / \mathrm{mL})$. This demonstrates that, although the strains had differing characteristics such as antimicrobial resistance, the inhibitory action of propolis ethanol extract was similar; suggesting that the mechanism of resistance to methicillin does not interfere with the antimicrobial activity of propolis.

The results obtained confirm an antimicrobial activity in relation to the strains of $S$. aureus tested, as described in the literature. The MIC found in this study is in accordance with some results reported in the literature $(6,10,12,13,15,16)$. Nevertheless, the variation in the MIC values in studies reported in the literature may have stemmed from the different methods used or variability in strains and propolis samples.

This result is significant, mainly in light of the variability in chemical composition of the different propolis samples as previously discussed. This is an important characteristic for an antimicrobial agent as it avoids the development of microbial resistance.

Although there are innumerable propolis-based products readily available nationally and internationally, in vivo clinical studies are needed to confirm results prior to clinical administration of propolis.

The chemical composition of the propolis sample and its ethanol extract showed that this was a mixture of BRP (SP/MG) and BRP (PR), as the samples had markers characteristic of both types.

The determination of type and quantification of bioactive components of these propolis samples will allow its use in pharmaceutical products, cosmetics, and in oral hygiene (9). A specific type of propolis may prove more suitable for each type of application.

\section{REFERENCES}

1. Bankova, V. (2005). Recent trends and important developments in propolis research. Evid Based Complement Alternat Med. 2: 29-32.

2. Bankova, V. (2005). Chemical diversity of propolis and the problem of standardization. J Ethnopharmacol. 100: 114-117. 
3. Clinical and Laboratory Standards Institute (2006). Methods for Dilution Antimicrobial Susceptibility Tests for Bacteria That Grow Aerobically; Approved Standard - Seventh Edition CLSI document M7-A7. Clinical and Laboratory Standards Institute. Wayne, Pennsylvania, United States.

4. Clinical and Laboratory Standards Institute (2009). Performance standards for antimicrobial susceptibility testing; Nineteenth informational supplement. CLSI document M100-S19. Clinical and Laboratory Standards Institute. Wayne, Pennsylvania, USA.

5. Fernandes Junior, A.; Balestrin, E.C.; Betoni, J.E.C.; Orsi, R.O.; Cunha, M.L.R.S.; Montelli, A.C. (2005). Propolis: anti-Staphylococcus aureus activity and synergism with antimicrobial drugs. Mem Inst Oswaldo Cruz.100: 563-566.

6. Fernandes Junior A.; Sugizaki M.F.; Fogo M.L.; Funari S.R.C; Lopes C.A.M. (1995). In vitro activity bacterial and yeast pathogens isolated from human infections. J. Venom. Anim. Toxins. 1(2) [quoted 8 Jan 2009]; Available from: http://www.scielo.br/scielo.php?script=sci arttext\&pid=S0104-79301995000200003

7. Kujumgiev, A., Tsvetkova, I., Serkedjieva, Y., Bankova, V., Christov, R., Popov, S. (1999) Antibacterial, antifungal and antiviral activity of propolis of different geographic origin. J Ethnopharmacol 64: 235-240.

8. Marcucci, M.C. (2000). Processo de identificação de tipagens da própolis brasileira. Pedido de patente no INPI (Brasil); PI0006272-3 A2.

9. Marcucci, M.C. (2008). Própolis tipificada: um novo caminho para a elaboração de medicamentos de origem natural, contendo este produto apícola. Rev Fitos. 1: 36-45.

10. Miorin, P.L.; Levy Junior, N.C.; Custodio, A.R.; Bretz, W.A.; Marcucci, M.C. (2003). Antibacterial activity of honey and propolis from Apis mellifera and Tetragonisca angustula against Staphylococcus aureus. J
Appl Microbiol. 95: 913-920.

11. Onlen, Y., Duran, N., Atik, E., Savas, 1., Altug, E., Yacan, S., Aslantas, O. (2007). Antibacterial activity of propolis against MRSA and synergism with topical mupirocin. J Altern Complement Med 13(7):713718.

12. Pepeljnjak S, Kokalec, I. (2004). Galangin expresses bactericidal activity against multiple-resistant bacteria: MRSA, Enterococcus spp. and Pseudomonas aeruginosa. FEMS Microbiol Lett. 240: 111-116.

13. Rezende, G.P.S.R.; Pimenta, F.C.; Costa, L.R.R.S. (2006). Antimicrobial activity of two Brazilian commercial propolis extracts. Braz J Oral Sci. 5(16): 967-970

14. Salatino, A., Teixeira, E.W., Negri, G., Message, D. (2005). Origin and chemical variation of Brazilian propolis. Evid Based Complement Alternat Med. 2: 33-38.

15. Salomão, K.; Dantas, A.P.; Borba, C.M.; Campos, L.C.; Machado, D.G.; Aquino Neto, F.R.; de Castro, S.L. (2004). Chemical composition and microbicidal activity of extracts from Brazilian and Bulgarian propolis. Lett Appl Microbiol. 38(2): 87-92.

16. Scazzochio, F.; D’Auria, F.D.; Alessandrini, D.; Pantanella, F. (2006). Multifactorial aspects of antimicrobial activity of propolis. Microbiol Res.;161: 327-333.

17. Stepanovic, S.; Antie, N.; Dakie, I.; Svabie-Vlahovic, M. (2003). In vitro antimicrobial activity of propolis and synergism between propolis and antimicrobial drugs. Microbiol Res. 158: 353-357.

18. Von Eiff, C.; Becker, K.; Machka, K.; Stammer, H.; Peters, G. (2001). Nasal carriage as a source of Staphylococcus aureus bacteremia. $N$ Engl J Med. 344: 11-16. 